\title{
Coefficient of Consolidation and its Correlation with Index Properties of Remolded Soils
}

\begin{abstract}
Knowledge of the rate at which the compression of the soil layer takes place is essential from design considerations. This can be achieved by determining the value of the coefficient of consolidation, $c_{v}$. To obtain $c_{v}$, it is essential to conduct a routine one-dimensional consolidation test. With the obtained time-compression data, and using any one of the several available curve-fitting procedures, $c_{v}$ can be evaluated. This is a time-consuming process. Also, the fact that many curve-fitting procedures are available in the literature suggests that none of them are completely satisfactory in evaluating $c_{v}$ and, hence, the large variation in the evaluated values by different procedures. Hence, it is desirable to predict the value of $c_{v}$ by any correlation equation relating with some simple index property. This will be quite satisfactory, especially so for preliminary assessment purposes. From the present experimental study on remolded soils, it is found that $c_{v}$ has a better correlation with the shrinkage index, which is the difference between liquid limit and shrinkage limit.
\end{abstract}

KEYWORDS: compressibility, rate of settlement, coefficient of consolidation, geotechnical engineering

\section{Introduction}

Founding of any structure on a compressible soil layer leads to its settlement. The amount of settlement is related to the compression index, $C_{c}$, or coefficient of volume change, $m_{v}$. Knowledge of the rate at which the compression of the soil layer takes place is essential from design considerations. This parameter assumes importance in the preloading technique for ground improvement. This can be achieved by determining the value of coefficient of consolidation, $c_{v}$. To obtain $c_{v}$, a routine one-dimensional consolidation test is usually performed. With the obtained time-compression data, and using any one of the several available curve-fitting procedures, $c_{v}$ can be evaluated. It may be seen from the literature (e.g., Olson 1986; Sridharan and Prakash 1995) that the suitability of any curve fitting procedure depends upon the soil type. Since many factors affect $c_{v}$, the experimental behavior of soil in the one-dimensional consolidation test does not completely match with the theoretical relationship of consolidation as obtained by Terzaghi's equation, which is made use of in the curve fitting procedures. In view of the complexity of obtaining $c_{v}$ from a consolidation test, any attempt to obtain the same from the correlation with the index properties for preliminary design will be most welcome.

\section{Prediction of Coefficient of Consolidation-State of the Art}

Many engineering properties are correlated with the index properties. Similarly, efforts, though limited, have been made in the past to predict coefficient of consolidation (Carrier 1985; Raju et al. 1995).

It appears that Carrier (1985) made an early attempt to predict coefficient of consolidation, $c_{v}$ (in $\mathrm{m}^{2} / \mathrm{s}$ ) as given by the following

Received August 27, 2001; accepted for publication March 12, 2004; published August 25, 2004.

${ }^{1}$ Professor, Department of Civil Engineering, Indian Institute of Science, Bangalore, India.

${ }^{2}$ Senior Lecturer, Department of Civil Engineering, BMS College of Engineering, Bangalore, India. equation:

$$
c_{v}=\frac{9.09 \times 10^{-7}\left(1.192+A C T^{-1}\right)^{6.993}\left(4.135 I_{L}+1\right)^{4.29}}{I_{p}\left(2.03 I_{L}+1.192+A C T^{-1}\right)^{7.993}}
$$

Where

$$
\begin{aligned}
A C T & =\text { Activity } \\
I_{L} & =\text { Liquidity index } \\
I_{P} & =\text { Plasticity index }
\end{aligned}
$$

It can be observed from Eq 1 that $c_{v}$ is inversely proportional to the plasticity index.

Raju et al. (1995) proposed an equation to predict $c_{v}$ (in $\mathrm{cm}^{2} / \mathrm{s}$ ) for a normally consolidated clay in terms of the void ratio at the liquid limit $\left(e_{L}\right)$ and the in situ effective overburden pressure, $\sigma_{v}^{\prime}$ $(\mathrm{kPa})$, given as:

$$
c_{v}=\frac{1+e_{L}\left(1.23-0.276 \log \sigma_{v}^{\prime}\right)}{e_{L}} \times \frac{1}{\sigma_{v}^{\prime(0.353)}} \times 10^{-3}
$$

The limitation of $\mathrm{Eq} 2$ is that it is from a limited study with four soils (liquid limit 50-106\% and plastic limit 27-47\%), and liquid limit is the only soil parameter considered. Soils can have the same liquid limit but a different plastic limit. Their behavior will be entirely different. Hence, the generalization is questionable.

Lambe and Whitman (1979) have given a typical range of values of coefficient of consolidation for soils of varying liquid limits as shown in Table 1.

Plasticity properties of the soils play a vital role in controlling the consolidation characteristics. Recently, Sridharan and Nagaraj (2000) have brought the role of plasticity properties in controlling the compressibility characteristics. They have shown that shrinkage index (liquid limit—shrinkage limit) has a better correlation with compressibility characteristics than the plasticity index or liquid limit of soils. In this paper, an attempt has been made to find which of the index properties/indices correlate better with coefficient of consolidation. 
TABLE 1-Typical values for Coefficient of Consolidation.

\begin{tabular}{rccc}
\hline $\begin{array}{c}\text { Liquid } \\
\text { Limit }\end{array}$ & $\begin{array}{c}\text { Lower Limit for } \\
\text { Recompression }\left(\mathrm{m}^{2} / \mathrm{s}\right)\end{array}$ & $\begin{array}{c}\text { Undisturbed Virgin } \\
\text { Compression }\left(\mathrm{m}^{2} / \mathrm{s}\right)\end{array}$ & $\begin{array}{c}\text { Upper Limit } \\
\text { Remolded }\left(\mathrm{m}^{2} / \mathrm{s}\right)\end{array}$ \\
\hline 30 & $3.5 \times 10^{-6}$ & $5 \times 10^{-7}$ & $1.2 \times 10^{-7}$ \\
60 & $3.5 \times 10^{-7}$ & $1 \times 10^{-7}$ & $3 \times 10^{-8}$ \\
100 & $4 \times 10^{-8}$ & $2 \times 10^{-8}$ & $1 \times 10^{-8}$ \\
\hline
\end{tabular}

Coefficient of consolidation $c_{v}$ (in $\mathrm{m}^{2} / \mathrm{s}$ ) can be expressed as:

$$
c_{v}=\frac{k}{m_{v} \gamma_{w}}
$$

Where

$$
\begin{aligned}
k & =\text { hydraulic conductivity }(\mathrm{m} / \mathrm{s}) \\
m_{v} & =\text { coefficient of volume change }\left(\mathrm{m}^{2} / \mathrm{kN}\right) \\
\gamma_{w} & =\text { unit weight of pore fluid }\left(\mathrm{kN} / \mathrm{m}^{3}\right)
\end{aligned}
$$

Terzaghi and Peck (1967) indicated that, with decreasing void ratio (i.e., with increasing effective vertical consolidation pressure, $\left.\sigma_{v}^{\prime}\right)$ both $k$ and $m_{v}$ decrease rapidly so that the ratio $\left(k / m_{v}\right)$ and, hence, $c_{v}$, is fairly constant over a wide range of effective vertical consolidation pressures. Though this is the general understanding about the variation of $c_{v}$ with pressure, recent findings of Robinson and Allam (1998) have shown that $c_{v}-\sigma_{v}^{\prime}$ relationship is affected by clay mineralogy and, hence, the soil type. This aspect has been studied in detail in this paper.

\section{Materials and Methods}

\section{Materials}

Ten soils, including a number of natural soils along with commercially available kaolinite, covering a wide range of liquid limits $\left(37 \% \leq w_{L} \leq 74 \%\right)$, were selected for the present study and have been tested for their physical properties according to ASTM standards and the results reported in Table 2.

The specific gravity was determined using a pycnometer (stoppered bottle having a capacity of $50 \mathrm{~mL}$ ) as specified by the ASTM Standard Test Method for Specific Gravity of Soils (D 854-92, 1995). The specific gravity values are an average of three tests; individual determinations differed from the mean by less than 0.01 . The liquid limit of soils was determined by the cone penetrometer method as specified by BS: 1377-part 2, 1990. The liquid limit tests were carried out to obtain a minimum of five points for plotting the flow curve. The consistency of the soil specimens was adjusted such that the cone penetration ranged between 15 and $25 \mathrm{~mm}$. The plastic limit of the soil specimens was determined by the rolling thread method as outlined in the ASTM Standard Test Method for Liquid Limit, Plastic Limit, and Plasticity Index of Soils (D 431893, 1995). The shrinkage limit of soil specimens was determined according to ASTM Test Method for Shrinkage Factors of Soils by the Mercury Method (D427-83, 1995). While placing the wet soil at its liquid limit water content into the shrinkage dish, care was taken to expel entrapped air. First allowing the soil to air dry under controlled conditions, and then oven drying to a constant mass prevented cracking due to fast drying. The shrinkage limits reported are the average of three determinations; the variation between individual determinations was less than $0.5 \%$.

Grain-size analysis was done according to ASTM Test Method for Particle Size Analysis of Soils (D 422-63, 1995) by wet sieving of $100 \mathrm{~g}$ of dry soil using a $75-\mu \mathrm{m}$ sieve. The portion retained on the $75-\mu \mathrm{m}$ sieve was oven dried and sieved using sieves of 300,212 , and $150-\mu \mathrm{m}$ sizes. The soil passing through $75-\mu \mathrm{m}$ was collected carefully and air-dried, and the grain-size distribution analysis was performed by the hydrometer method. The results are presented in Table 1 .

The mineralogical analysis of the soils was performed using

\begin{tabular}{|c|c|c|c|c|c|c|c|c|c|c|c|c|c|}
\hline \multirow{2}{*}{$\begin{array}{l}\text { Soil } \\
\text { No. }\end{array}$} & \multirow{2}{*}{$\begin{array}{l}\text { Soil } \\
\text { Type }\end{array}$} & \multirow[b]{2}{*}{$G_{s}^{*}$} & \multirow[b]{2}{*}{$w_{L}(\%)$} & \multirow[b]{2}{*}{$w_{P}(\%)$} & \multirow[b]{2}{*}{$w_{S}(\%)$} & \multirow[b]{2}{*}{$I_{P}(\%)$} & \multirow[b]{2}{*}{$I_{S}(\%)$} & \multirow[b]{2}{*}{$e_{L}$} & \multirow[b]{2}{*}{$e_{S}$} & \multicolumn{3}{|c|}{ Grain Size Distribution } & \multirow[b]{2}{*}{ Mineralogy } \\
\hline & & & & & & & & & & Sand $(\%)$ & Silt $(\%)$ & Clay $(\%)$ & \\
\hline 1 & Red Earth-1 & 2.70 & 37.0 & 18.0 & 14.7 & 19.0 & 22.3 & 0.99 & 0.39 & 35.5 & 38.5 & 26.0 & $\begin{array}{l}\text { kaolinite, } \\
\text { montmorillonite, } \\
\text { muscovite, quartz }\end{array}$ \\
\hline 2 & Silty soil-1 & 2.65 & 39.0 & 29.5 & 27.4 & 9.5 & 11.6 & 1.03 & 0.73 & 36.5 & 58.5 & 5.0 & Illite, quartz \\
\hline 3 & Kaolinite-1 & 2.65 & 48.0 & 35.6 & 39.0 & 12.4 & 9.0 & 1.27 & 1.03 & 16.0 & 74.5 & 9.5 & kaolinite, quartz \\
\hline 4 & Red Earth-2 & 2.70 & 48.0 & 23.2 & 15.5 & 24.8 & 32.5 & 1.29 & 0.42 & 8.0 & 57.0 & 35.0 & $\begin{array}{l}\text { kaolinite, } \\
\text { montmorillonite, } \\
\text { muscovite,quartz }\end{array}$ \\
\hline 5 & Kaolinite-2 & 2.64 & 55.0 & 31.4 & 33.1 & 23.6 & 21.9 & 1.45 & 0.87 & 1.0 & 67.0 & 32.0 & kaolinite, quartz \\
\hline 6 & Cochin clay & 2.61 & 56.4 & 38.1 & 21.0 & 18.3 & 35.4 & 1.47 & 0.55 & 18.0 & 64.5 & 17.5 & Illite \\
\hline 7 & Brown soil-1 & 2.66 & 58.5 & 32.1 & 13.5 & 26.4 & 45.0 & 1.56 & 0.36 & 19.5 & 42.5 & 35.0 & $\begin{array}{l}\text { Montmorillonite, } \\
\text { kaolinite muscovite, } \\
\text { quartz }\end{array}$ \\
\hline 8 & Kaolinite-3 & 2.65 & 58.7 & 45.2 & 46.4 & 13.5 & 12.3 & 1.56 & 1.23 & 0.0 & 88.5 & 11.5 & kaolinite, quartz \\
\hline 9 & Illitic soil & 2.58 & 73.4 & 51.9 & 39.0 & 21.5 & 34.4 & 1.89 & 1.01 & 0.9 & 71.6 & 27.5 & Illite, kaolinite, quartz \\
\hline 10 & B C soil-1 & 2.70 & 73.5 & 35.6 & 11.9 & 37.9 & 61.6 & 1.98 & 0.32 & 13.0 & 35.5 & 51.5 & Montmorillonite, quartz \\
\hline
\end{tabular}
an $\mathrm{X}$-ray diffractometer with $\mathrm{Cu}-\mathrm{k} \alpha$ radiation. The principal clay minerals present in the soils are given in Table 1.

TABLE 2-Index properties of soils used.

Note:*

$G_{S}=$ Specific gravity

$w_{L}=$ Liquid limit

$w_{P}=$ Plastic limit

$w_{S}=$ Shrinkage limit

$I_{P}=$ Plasticity index

$I_{S}=$ hrinkage index

$e_{L}=$ Void ratio at liquid limit

$e_{S}=$ Void ratio at shrinkage limit 


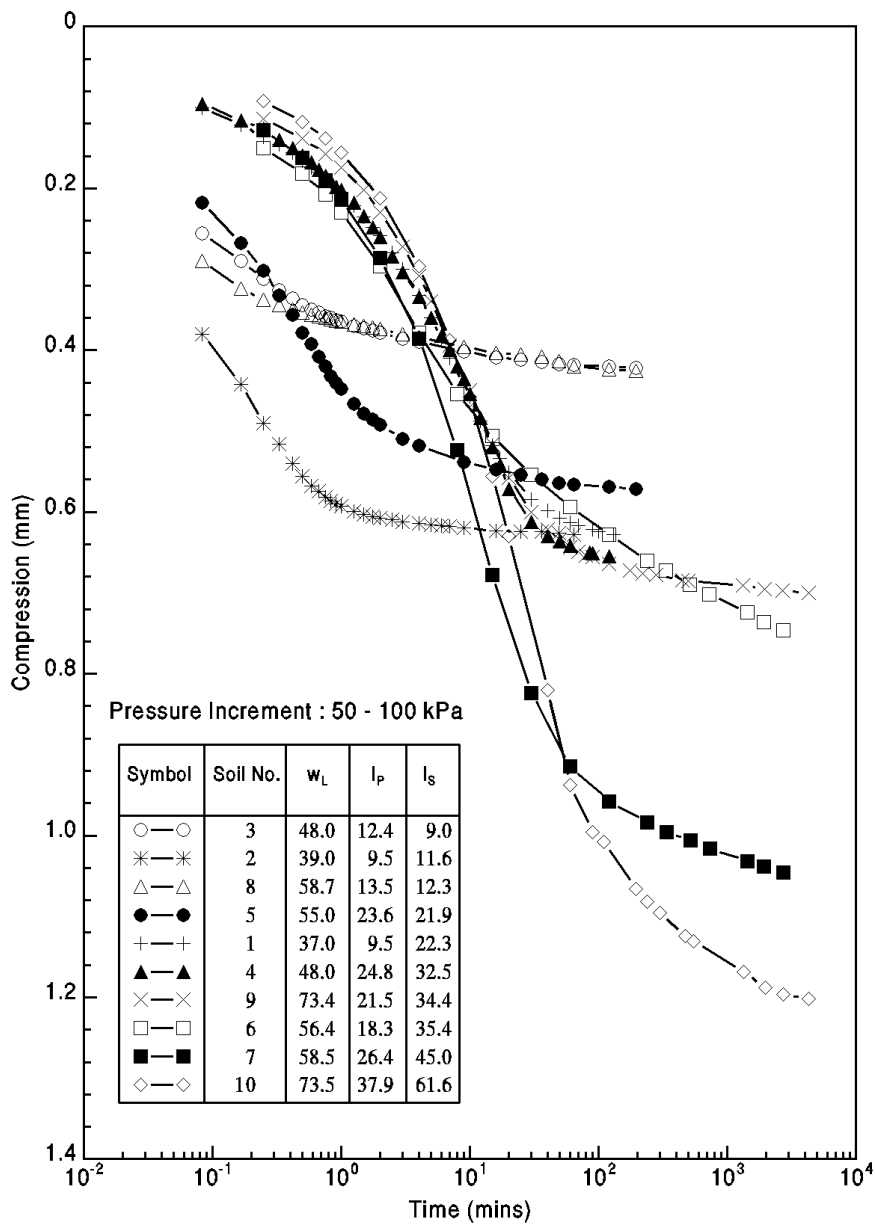

FIG. 1-Typical time-compression curves of ten soils having different plasticity characteristics for a pressure increment of 50-100 kPa.

\section{One-Dimensional Consolidation Tests}

The soils were tested in standard fixed ring consolidometers using stainless steel rings, $60 \mathrm{~mm}$ in diameter and $20 \mathrm{~mm}$ high according to ASTM Standard Test Method for One-Dimensional Consolidation properties of soils (D 2435-90, 1995). The inside of the rings was lubricated with silicone grease to minimize side friction between the ring and the soil specimen. The consolidation tests were conducted in a room maintained at a uniform temperature of $20^{\circ} \pm 1^{\circ} \mathrm{C}$.

Taking into consideration initial moisture content, which is an important parameter controlling the compressibility, the soil specimens were remolded at their respective liquid limit. The initial water content was set equal to the liquid limit, primarily because it is the extreme limiting water content above which the soil is about to flow. These soil specimens were hand remolded in the consolidation rings to a thickness of $20 \mathrm{~mm}$, taking care to prevent any air entrapment in the specimens. Filter papers were positioned on the top and bottom of the soil specimens to prevent particles from being forced into the pores of the porous stones placed on both sides of the specimen. The porous stones were kept in distilled water for a sufficient time, and were used in damp condition to avoid absorption of water from the sample. Each ring with the sample prepared as described above was placed in a consolidation cell and screwed tightly to the close fitting metal jacket on top of the cell. The cell was next mounted and positioned on a loading frame with a

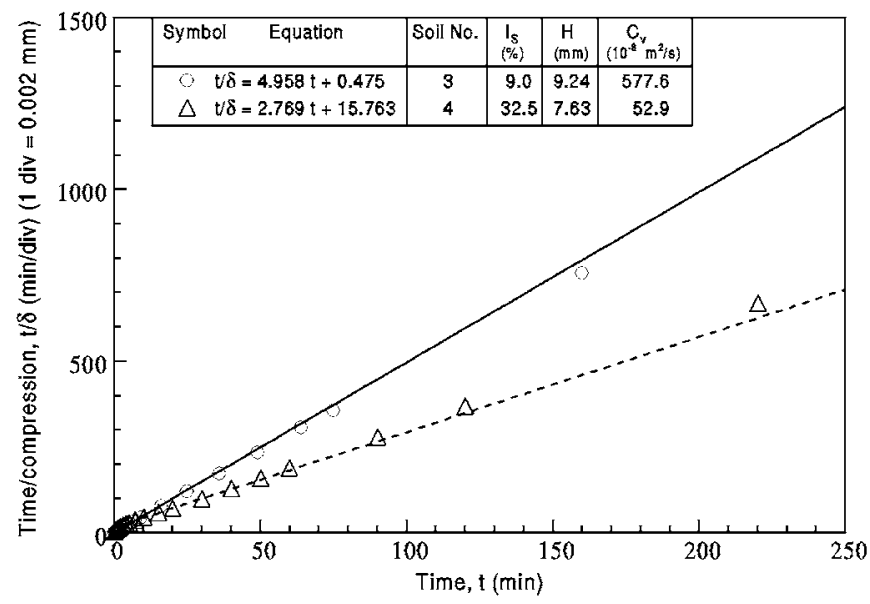

(a)

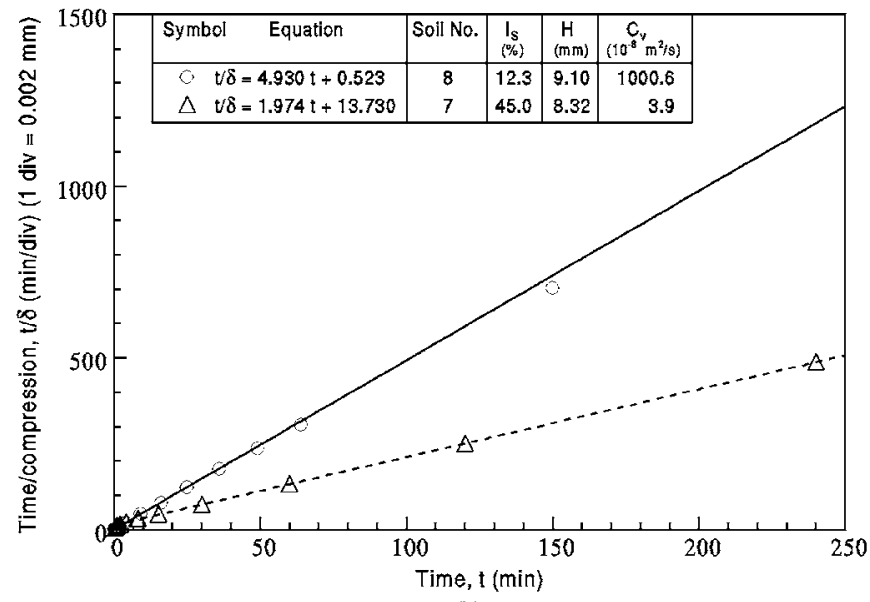

(b)

FIG. 2-(a) Typical time/compression versus time plots of the two soils having different plasticity characteristics for a pressure increment of 50$100 \mathrm{kPa}$; (b) Typical time/compression versus time plots of the two soils having different plasticity characteristics for a pressure increment of 50$100 \mathrm{kPa}$.

vertical deflection dial gage properly adjusted and fixed in position to give proper dial reading under application of load. The cell was inundated with distilled water and a nominal load of $6.25 \mathrm{kPa}$ was applied. Care was taken to replenish any evaporated water.

After equilibrium was attained as indicated by the nearly constant readings on the dial gage, conventional oedometer tests were carried out. A load increment ratio of unity was adopted and each load maintained until near equilibrium had been attained. Each specimen was loaded to a maximum of $800 \mathrm{kPa}$ and later unloaded with a load decrement ratio of unity.

\section{Results and Discussion}

From the one-dimensional consolidation tests done on each of the ten soils, the $c_{v}$ values were calculated using rectangular hyperbola method (Sridharan et al. 1987; Bowles 1996). Figure 1 shows a time-compression plot of all the ten soils tested in the present study for a pressure increment of $50-100 \mathrm{kPa}$. Similar results have been obtained for other pressure increments. Figures $2 a$ and $b$ show the time/compression versus time plots of the data presented in Fig. 1. From these plots, $c_{v}$ values were calculated using rectangular hyperbola method. Values of $c_{v}$ for Soil Nos. 3, 4, 8, and 7 in the pressure range of $50-100 \mathrm{kPa}$ are shown in Figs. $2 a$ and $b$. 

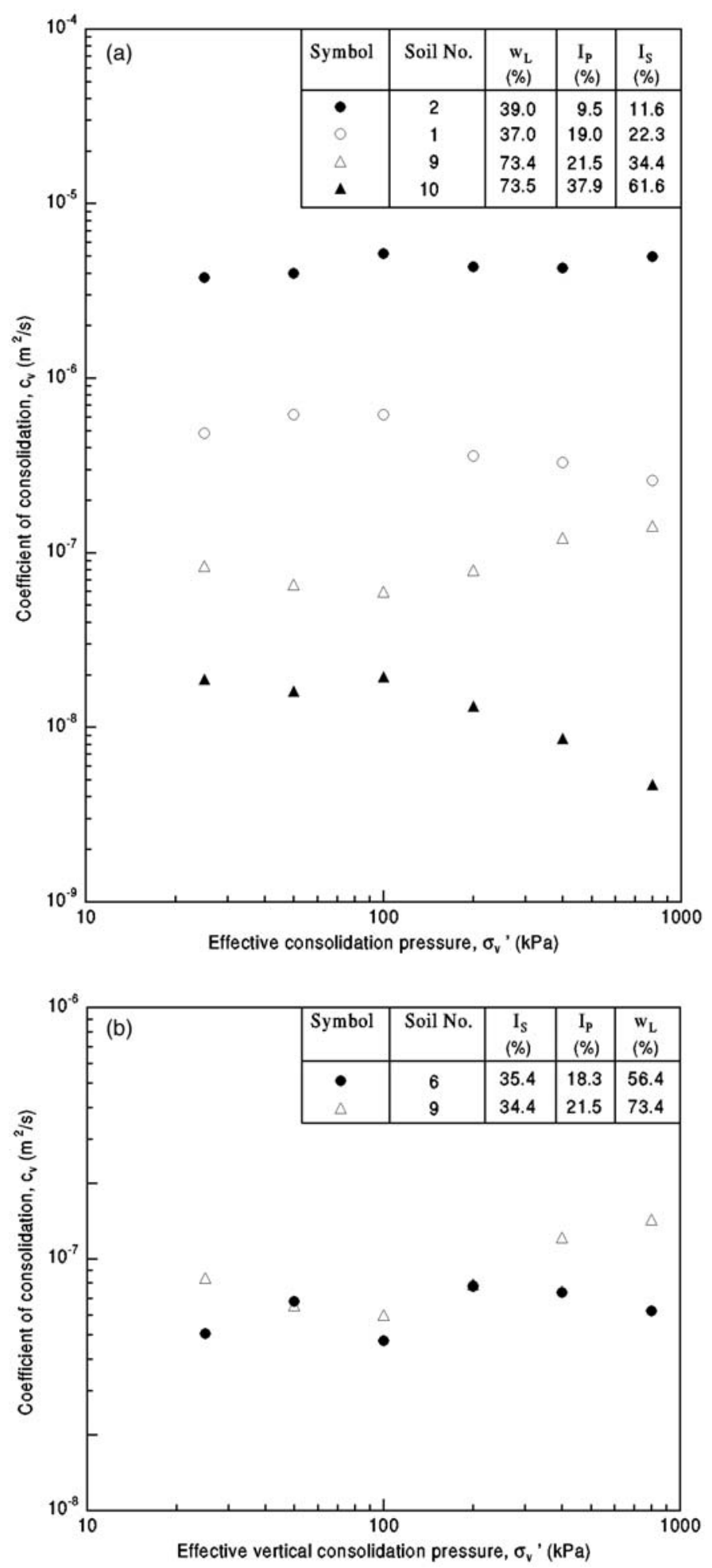

FIG. 3-(a) Effective vertical consolidation pressure versus coefficient of consolidation of two sets of two soils each having liquid limit approximately 38 and $74 \%$; (b) Effective vertical consolidation pressure versus coefficient of consolidation of a set of two soils having shrinkage index approximately $35 \%$.

It is a usual practice to plot the experimentally obtained $c_{v}$ as a function of applied effective vertical consolidation pressure $\left(\sigma_{v}^{\prime}\right)$. Figure $3 a$ shows the plot of $c_{v}$ versus effective consolidation pressure on log-log plot for the two pairs of soils having nearly the same liquid limit $w_{L}$ nearly equal to 39 and $74 \%$ ), but different plasticity characteristics. From the figure, it is clear that even though the liquid limit of the pairs of soil is nearly the same, the $c_{v}$ versus $\sigma_{v}^{\prime}$ relationship is different. For the soil pairs having nearly the same liquid limit, the measured $c_{v}$ values are one order of magnitude lower for the soil with a higher shrinkage index. It can also be observed that for the soils having nearly the same liquid limit, soil with lesser shrinkage index or plasticity index shows an increasing trend of $c_{v}$ versus $\sigma_{v}^{\prime}$. Whether soil with higher shrinkage index or plasticity index, there is a decreasing trend of $c_{v}$ versus $\sigma_{v}^{\prime}$. Similar results were obtained for other three pairs of soils. Further, it can be seen from Fig. $3 b$, which is Plot $c_{v}$ versus effective consolidation pressure on a log-log plot of two soils having nearly the same shrinkage index $\left(I_{S}\right.$ nearly equal to $\left.35 \%\right)$ but having different liquid limits, that these soils have a similar range of $c_{v}$ versus effective consolidation pressure.

Recently, Robinson and Allam (1998) have studied the variation of $c_{v}$ versus $\sigma_{v}^{\prime}$. They have discussed the role of mineralogy and the mechanical and physico-chemical factors on the $c_{v}$ versus $\sigma_{v}^{\prime}$ behavior. They have concluded that the increasing behavior of $c_{v}$ versus $\sigma_{v}^{\prime}$ is due to the compressibility of such soils being
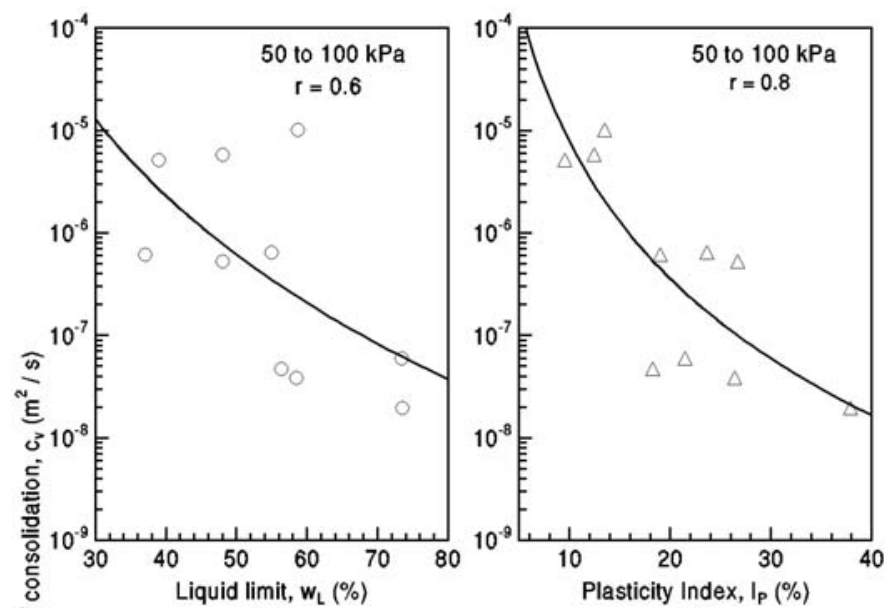

(a)

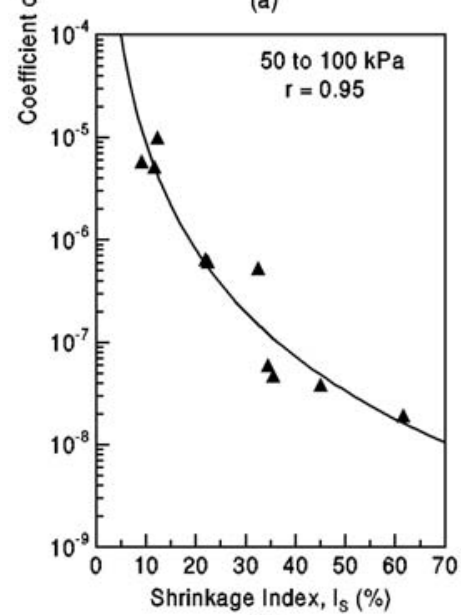

(c)

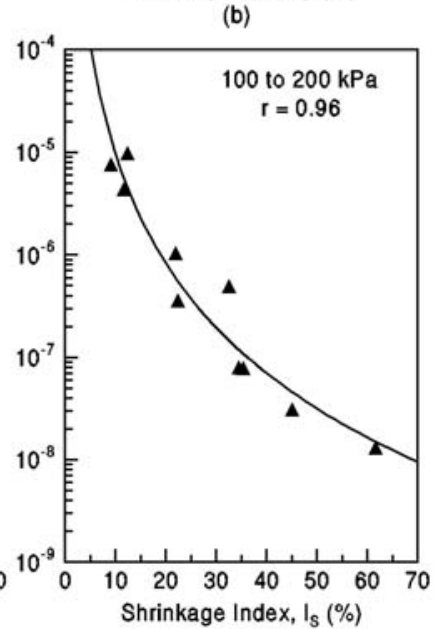

(d)

FIG. 4-(a) Relationship between the coefficient of consolidation and the liquid limit for a pressure increment of 50-100 kPa; (b) Relationship between the coefficient of consolidation and the plasticity index for a pressure increment of 50-100 kPa; (c) Relationship between the coefficient of consolidation and the shrinkage index for a pressure increment of 50-100 kPa; (d) Relationship between the coefficient of consolidation and the shrinkage index for a pressure increment of 100-200 kPa. 


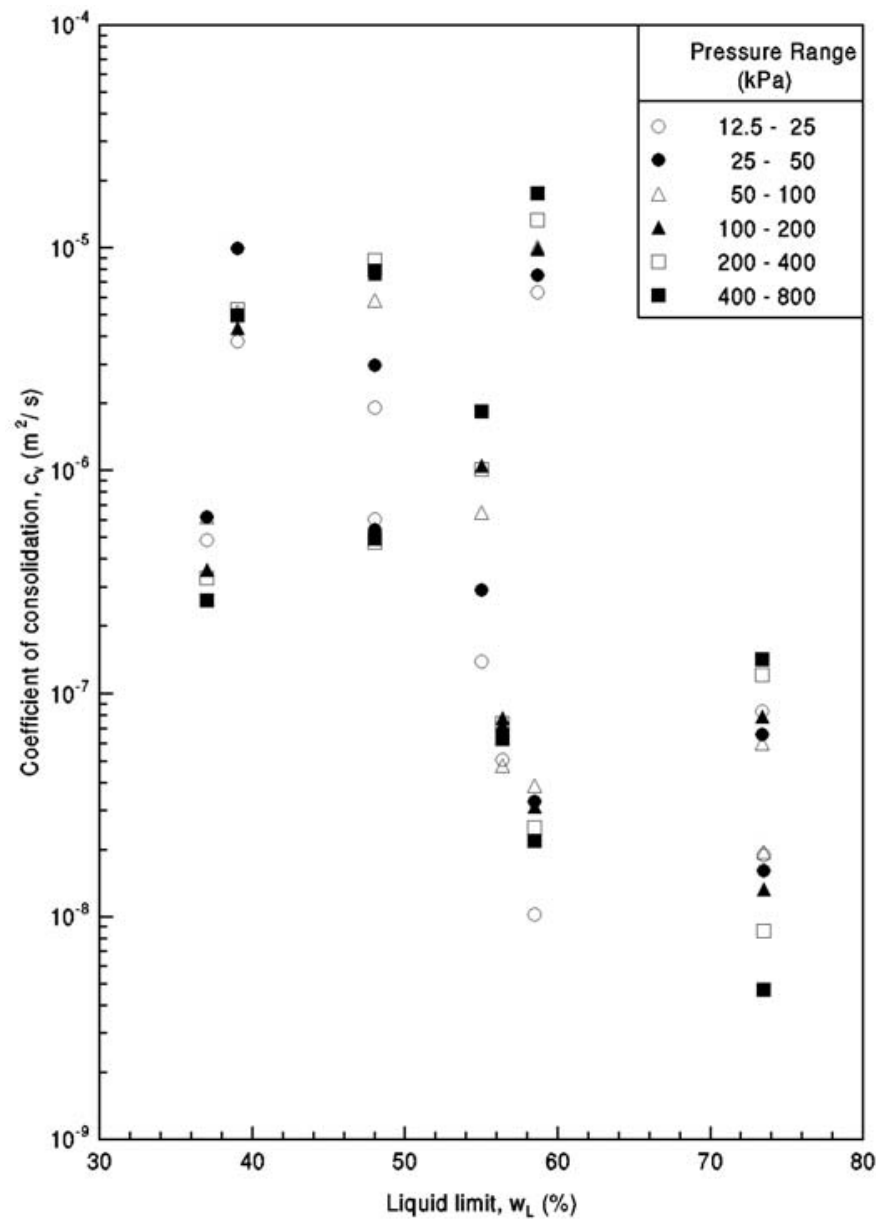

FIG. 5-Relationship between the coefficient of consolidation and the liquid limit for various effective vertical consolidation pressures.

governed by mechanical factors, and the opposite behavior for soils whose compressibility behavior is controlled by physico-chemical factors.

It is well known that the coefficient of consolidation is a parameter that indicates the rate of compression of a saturated soil undergoing compression, which in turn directly depends on the hydraulic conductivity of the soil medium undergoing compression (refer to Eq 3). The authors feel that for a soil that is more plastic as indicated by higher plasticity index or shrinkage index, hydraulic conductivity of the soil at any stress level will be less as compared to a soil that is less plastic. The reason being that the thickness of diffuse double layer (ddl) will be relatively larger for a highly plastic soil as compared to a less plastic soil. The thicker the ddl, the greater the reduction in the effective pore size for flow, and hence, reduction in the hydraulic conductivity of soil. The authors feel that this may be the reason for $c_{v}$ values being relatively higher for less plastic soils than for more plastic soils, though their liquid limit is nearly the same.

The authors also feel that as the effective consolidation pressure for a normally consolidated soil increases, the soil particles become more oriented and also come close to each other. As a consequence, for more plastic soils, the diffuse double layer repulsive forces mobilize, acting against the external loading, and hence, offer more resistance to compression (both rate and amount). This may be the reason for the decreasing trend of $c_{v}$ versus $\sigma_{v}^{\prime}$ for more plastic soils. In the case of less plastic soils whose compressibility behav-

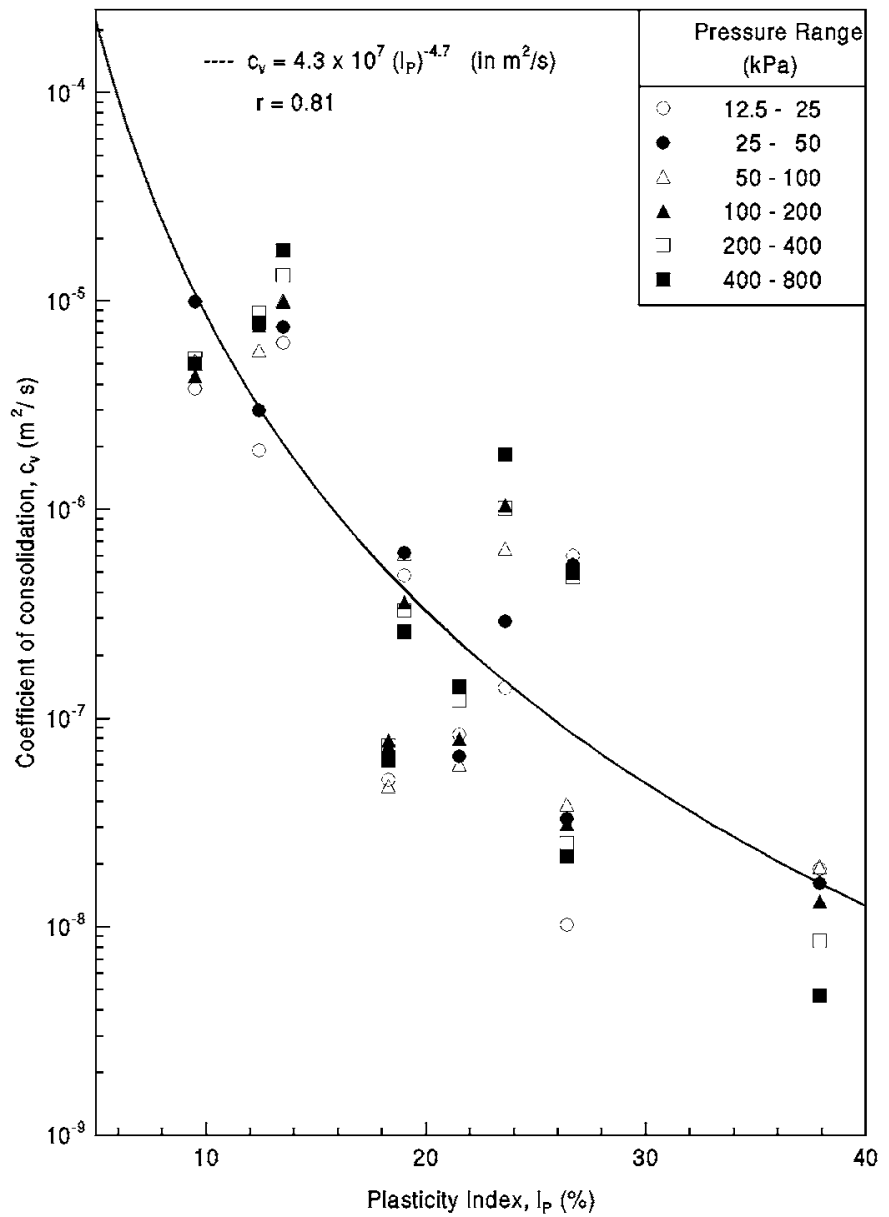

FIG. 6-Relationship between the coefficient of consolidation and the plasticity index for various effective vertical consolidation pressures.

ior is governed mainly by mechanical forces, as the consolidation pressure increases, the gravitational forces increase and will override the little repulsive pressure at the particle level in retarding the compression of soil, and hence, the increase in the rate of compression of the soil, i.e., an increase in $c_{v}$ with pressure. This explains the varying trends of $c_{v}$ versus $\sigma_{v}^{\prime}$ for soils with different plasticity properties.

The following paragraphs discuss which index parameter correlates better with $c_{v}$. Figures $4 a$ and $b$ show the variation of $c_{v}$ with liquid limit and plasticity index, respectively, for a pressure increment of $50-100 \mathrm{kPa}$. Similarly, Figs. $4 c$ and $d$ show the variations of $c_{v}$ with shrinkage index for pressure increment of $50-100 \mathrm{kPa}$ and $100-200 \mathrm{kPa}$, respectively. It can be observed from Fig. $4 a$ that scatter is more in $c_{v}$ values with the liquid limit and, therefore, correlation is poor. Further, from Fig. $4 b$, it is clear that a better correlation exists between $c_{v}$ and the plasticity index, as compared to $c_{v}$ versus the liquid limit. Lastly, from Figs. $4 c$ and $d$, it is evident that the correlation between $c_{v}$ and shrinkage index is better either than plasticity index or liquid limit. Similar behavior is observed for all pressure ranges. Further, to propose a correlation equation for predicting $c_{v}$, the results of variation of $c_{v}$ with effective vertical consolidation pressure is plotted against the index parameters namely, the liquid limit, the plasticity index, and shrinkage index, as shown in Figs. 5, 6, and 7, respectively. From these figures, it is clear that the scatter is the least in the case of shrinkage index (Fig. 7), and the correlation is better with a correlation coefficient, 


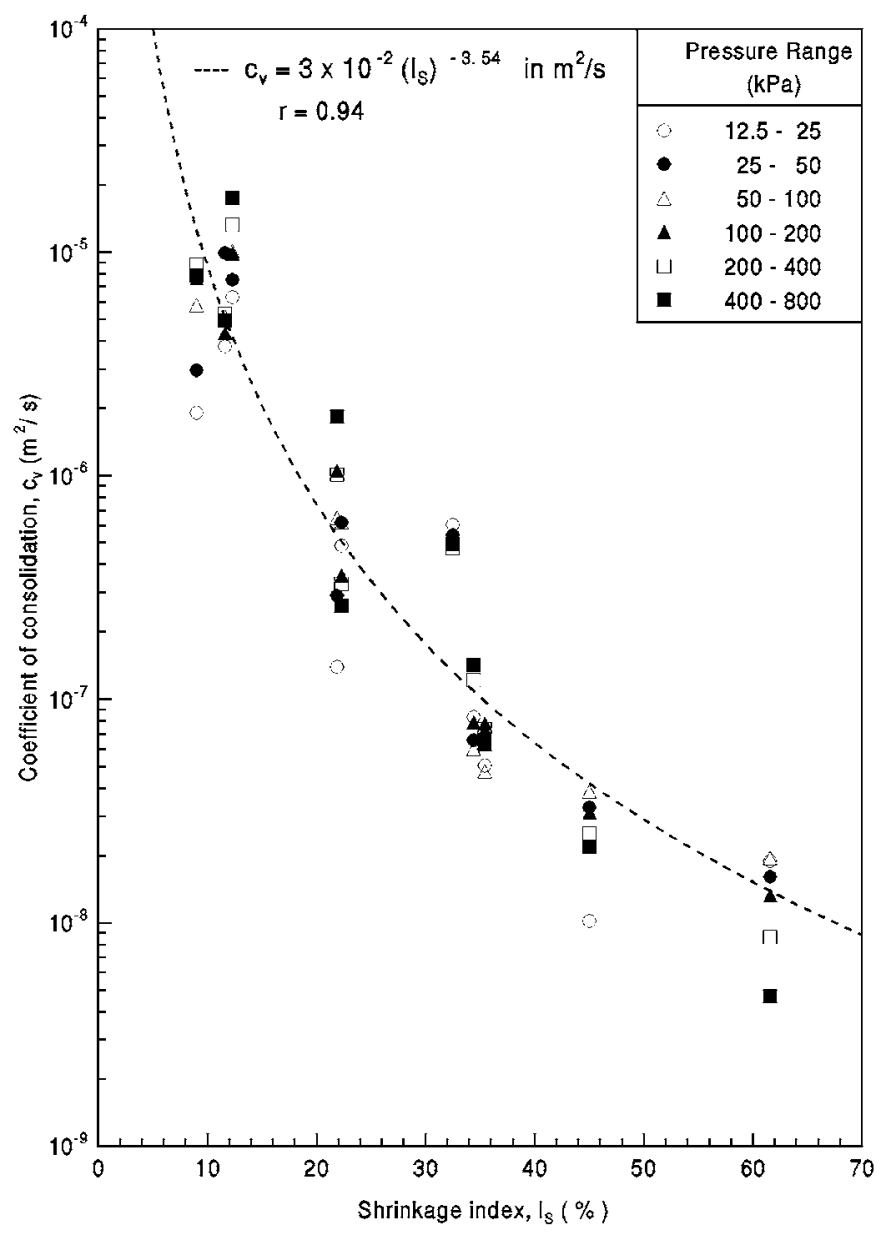

FIG. 7-Relationship between the coefficient of consolidation and the shrinkage index for various effective vertical consolidation pressures.

$r=0.94$, and the equation is given as:

$$
c_{v}=\frac{3}{100\left(I_{S}\right)^{3.54}}
$$

Where, $c_{v}=$ coefficient of consolidation in $\mathrm{m}^{2} / \mathrm{s}$.

Earlier, Carrier (1985) in his empirical study has shown that the plasticity index controls $c_{v}$, and they are inversely related. From the present study, it has become clear that shrinkage index is a better correlative parameter than the plasticity index in predicting $c_{v}$ as given by Eq 4.

It can be mentioned here that though coefficient of consolidation has a better correlation with shrinkage index than plasticity index, in the absence of shrinkage limit data, which is normally not determined in routine testing of soils as compared to plastic limit, the correlation between $c_{v}$ and plasticity index, although less strong, can be used for prediction purposes.

\section{Conclusions}

In this paper an attempt has been made to explain more logically the variations in the values of $c_{v}$ and also the varying trends of $c_{v}$ versus the effective vertical consolidation pressure for soils with different plasticity properties, though the liquid limit of the soils are nearly the same. The inferences and conclusions drawn are based on results obtained from remolded soils. They need to be verified for undisturbed and overconsolidated soils. Based on the results, a better correlation equation has been proposed to predict $c_{v}$ in terms of shrinkage index. However, in the absence of shrinkage limit data, which is normally not determined in routine testing of soils as compared to plastic limit, the correlation between coefficient of consolidation and plasticity index, although less strong, can be used for prediction purposes.

\section{References}

Bowles, J. E., 1996, Foundation Analysis and Design, McGraw Hill Book Company, New York, pp. 66-68.

Carrier, W. D., III, 1985, "Consolidation Parameters Derived From Index Tests," Geotechnique, Vol. 35, No. 2, pp. 211213.

Lambe, T. W. and Whitman, R. V., 1979, Soil Mechanics, John Wiley and Sons, New York.

Leonards, G. A. and Ramiah, B. K., 1959, "Time Effects in the Consolidation of Clays," Symposium on Time Rates of Loading in Soil Testing, ASTM STP 254, pp. 116-130.

Olson, R. E., 1986, "State of Art: Consolidation Testing, Consolidation of Soils, Testing and Evaluation," ASTM STP 892, R. N. Yong and F. C. Townsend, Eds., pp. 7-70.

Raju Narasimha, P. S. R., Pandian, N. S., and Nagaraj, T. S., 1995, "Analysis and Estimation of Coefficient of Consolidation," Geotechnical Testing Journal, Vol. 18, No. 2, pp. 252258.

Robinson, R. G. and Allam, M. M., 1998, "Effect of Clay Mineralogy on Coefficient of Consolidation," Clays and Clay Minerals, Vol. 46, No. 5, pp. 596-600.

Sridharan, A., Murthy, N. S., and Prakash, K., 1987, "Rectangular Hyperbola Method of Consolidation Analysis," Geotechnique, Vol. 37, No. 3, pp. 355-368.

Sridharan, A. and Prakash, K., 1995, "Critical Appraisal of Laboratory Determination of $\mathrm{c}_{v}$," International Symposium on Compression and Consolidation of Clayey Soils, Hiroshima, Japan, Balkema Publishers, pp. 567-572.

Sridharan, A. and Nagaraj, H. B., 2000, "Compressibility Behaviour of Remoulded, Fine-Grained Soils and Correlation with Index Properties," Canadian Geotechnical Journal, Vol. 37, No. 2, pp. 712-722.

Terzaghi, K. and Peck, R. B., 1967, Soil Mechanics in Engineering Practice, John Wiley and Sons, New York. 